\title{
Sentinel lymph node - historical background and current views on its significance in complex management of breast cancer patients
}

\author{
Kubikova $\mathrm{E}^{1}$, Badidova $\mathrm{J}^{2}$, Klein $\mathrm{M}^{3}$, Beder $\mathrm{I} \mathrm{Jr}^{4}$, Benus $\mathrm{R}^{5}$, Polak $\mathrm{S}^{3}$, Varga $\mathrm{I}^{3}$ \\ Institute of Anatomy, Faculty of Medicine, Comenius University in Bratislava, Slovakia. \\ eliska.kubikova@fmed.uniba.sk
}

\begin{abstract}
Nowadays, breast cancer is the leading oncological diagnosis in women worldwide. On the other hand, breast cancer treatment can be considered one of the most progressive therapeutic approach in the medical field of oncology. The invasive types of breast cancer have a tendency to spread via lymphatic route, what brings in the issue of sentinel lymph node - the first node into which the lymph drains from a given anatomical location. This review paper discusses the historical background of the concept of sentinel lymph node and focuses on clinical significance of the positivity of sentinel lymph node(s) as well. Modern-day conservative therapeutic surgery of breast cancer should be in accordance with diagnostic and preventive interventions in the axilla, whose rate of invasiveness and morbidity must be also attenuated without worsening the patient's prognosis and survival rate. Formerly, a complete axillary lymph node dissection was routinely performed for prophylactic and cancer staging purposes. The indiscriminate application of this approach was replaced by sentinel lymph node biopsy. Along with common histopathological examination, immunohistochemistry, as well as modern techniques of molecular biology are often employed. These state-of-the-art methods enabled the identification of micrometastases, or even nanometastases, though their real prognostic value is yet to be concluded (Ref. 52). Text in PDF www.elis.sk. KEY WORDS: sentinel node, breast cancer, biopsy, historical background.
\end{abstract}

\section{Introduction}

The term sentinel lymph node was used for the first time by A. E. Gould in the context of his study of parotid gland carcinoma in 1960 (Gould et al, 1960). The issue of sentinel lymph nodes takes the stage in patients with malignant metastatic neoplasms, which have a tendency to spread via lymphatic route. In this metastatic process, a sentinel lymph node represents the first line of defense - it is the lymph node(s) in close vicinity to primary tumor, which is the first to receive lymphatic drainage from given anatomical location (Cabanas, 1992). The principal issue of the clinical practice utilizing this approach in cancer diagnostics, is the accurate identification of the lymphatic route form the site of primary tumor to the first (i.e. sentinel) lymph node, while at the same time limiting the false negative rate to maximum

${ }^{1}$ Institute of Anatomy, Faculty of Medicine, Comenius University in Bratislava, Slovakia, ${ }^{2}$ Department of Gynaecology and Obstetrics, General Hospital in Galanta, Slovakia, ${ }^{3}$ Institute of Histology and Embryology, Faculty of Medicine, Comenius University in Bratislava, Slovakia, ${ }^{4}$ Department of Paediatric Surgery, Faculty of Medicine, Comenius University in Bratislava and The National Institute of Children's Diseases, Bratislava, Slovakia, and ${ }^{5}$ Department of Anthropology, Faculty of Natural Sciences, Comenius University in Bratislava, Slovakia

Address for correspondence: E. Kubíková, MD, PhD, Institute of Anatomy, Faculty of Medicine, Comenius University in Bratislava, Sasinkova 2, SK-811 04 Bratislava, Slovakia. extent (Lee et al, 2009; Whitman et al, 2019). The most commonly used methods are visualization of the lymphatic vasculature topography and sentinel lymph node related to the primary tumor using lymphotropic dyes (lymphography) or radiocolloids (lymphoscintigraphy), but currently also imaging modalities as ultrasound, single-photon emission computed tomography, magnetic resonance imaging and hybrid imaging methods are used (Niebling et al, 2016, Joseph et al, 2017). The proper identification and subsequent histopathological evaluation of the sentinel lymph node bioptic sample is beneficial not only in the process of cancer staging, but also from the perspective of decision making concerning a radical surgery (Dumitru et al, 2018). What may pose as a problem, is the lack of protocol standardization between hospitals, leading to different surgical strategies with variable outcomes (Bolster et al, 2006). Diagnosis of metastatic affection of the sentinel lymph node is inevitable for the surgical treatment to be consistent with the principle of lege artis. The most common ambivalence in this regard is the necessity of complete axillary lymph node dissection (lymphadenectomy) versus more conservative approaches (Ebner et al, 2017). The accurate sentinel lymph node biopsy is a possibility for a patient to avoid unnecessary "overtreatment" what is the case of complete axillary lymph node dissection in patients with negative sentinel lymph node. These patients can be treated more conservatively with similar outcomes, but without complications, commonly accompanying radical surgery (Huang et al, 2016, Choi et al, 2018). A complete 
axillary lymph node dissection in combination with a damage of lymphatic vasculature frequently results in lymphedema or axillary web syndrome, conditions which are potentially mutilating and can lead to disability (Gillespie et al, 2018, Koehler et al, 2018). Highly advantageous is that sentinel lymph node biopsy has a widespread application in the management of multiple oncological conditions, though in our review paper, we focus specifically on invasive breast cancer.

\section{Historical background of breast cancer treatment}

Breast cancer and axillary lymph node surgery have more than 100 years of history. Until that time, breast cancer "treatment" was based on various "charlatanic methods", e.g. application of mercury, or inoculation of a patient with etiological agent of malaria, allegedly capable of treating the carcinoma. Interestingly, well-preserved studies from these "times of darkness" are available for further study. One example for all, is the study authored by the first head of the Institute of Anatomy, established in the territory of present-day Slovakia, within the Faculty of Medicine of the University of Trnava (1769-1777) - professor Wenzel Trnka von Krzowitz (Czech: Václav Trnka z Křovic, 1739-1791). He was born in present-day Czech Republic, graduated from a Viennese medical school, later worked in Trnava as a Professor of Anatomy for several years, until he became the founder of Hungarian anatomy. Later after the University of Trnava, he was relocated to Buda, and then to Pest - separate towns at that time, later unified into today's capital of Hungary - Budapest (RozsívalováLenzová, 1950, Varga et al, 2018, Kachlik et al, 2019). For better illustration of the means of breast cancer treatment in our territory during 18th century, we present an abridgement from the first textbook by Professor Wenzel Trnka von Krzowitz focused on intermittent fever from 1775 entitled "Historia febrium intermittentium omnis aevi observata et inventa illustriora medica ad has febres pertinentia complectens". The Latin excerpt from this textbook can be loosely translated as follows: "According to observations, it can be stated that intermittent fever eliminates various tumors. A Vestal Virgin survived the amputation of her left breast, which became scirrhous (a term of Latin origin, describing hard tumor, composed predominantly of connective tissue). Despite both external and internal application of mercury, the right breast also became scirrhous shortly after. Eventually, she developed three-day fever lasting for several weeks, which resolved the scirrhus altogether - as described by Collin. Multiple similar cases were also documented after four-day fever".

This Trnka's work was cited also by prominent German bacteriologist Friedrich Loeffler (1852 - 1915), who repeatedly mentioned in his works, that Trnka experimented with the inoculation of the etiological agent of malaria in patients with an oncological disease. Strange as it may sound from the perspective of current knowledge, it was actually confirmed that cancer cells and some parasites have similar antigenic characteristics. On top of that, parasites Trypanosoma cruzi, Toxoplasma gondii, Toxocara canis, Acantamoeba castellani and Plasmodium yoelii showed antitumor activity in animal models (Darani and Yousefi, 2012).
At the beginning of the 20th century, basically until the 1970s, the only option of surgical treatment of breast cancer patients was, from the cosmetic point of view, considerably mutilating mastectomy, which included the removal of musculus pectoralis minor et major, axillary dissection, as well as the removal of intramammary lymph nodes. This radical surgery was adopted into practice by American physician William Stewart Halsted (1852-1922), whose surgical practice was well-founded by theoretical knowledge (Halsted et al, 2014, Wright, 2018). Between 1878 and 1880, he attended research fellowships across Europe in such world-acclaimed experts as Zuckerkandl (an Austrian physician who was the first to describe paraganglion at the bifurcation of the aorta, eponymously termed the Organ of Zuckerkandl), Kaposi (he was the first to describe Kaposi's sarcoma), Chiari (he described a condition of the cerebellum, known today as Chiari malformation), Billroth (the discoverer of the Cords of Billroth within the spleen), or Mikulicz (he introduced the surgical removal of a part of the large intestine). In Germany, he also worked under various big names, such as Professor Kölliker (the founder of modern embryology), military surgeon Esmarch (Esmarch's bandage for surgical haemostasis), or surgeon Thiersch (he implemented antiseptic methods and application of skin grafts) (Osborne, 2007).

\section{The beginning of the sentinel node concept}

In 1980, the results of a large-scale study NSABP B-04 (National Adjuvant Breast and Bowel Project Protocol No. B-04) were published. This study analyzed data obtained from 1665 women with primary breast carcinoma surgically treated in 34 specialized centers in Canada and United States (Fisher et al, 1980). These results called the attention to a significant finding - in about $70-80 \%$ of patients, complete axillary lymph node dissection represents an unnecessary overtreatment without any noticeable benefit, but at the same time, it is a procedure with substantial patient morbidity. Despite these conclusions, until the beginning of the 21 st century, lymphadenectomy of level I and level II axillary lymph nodes had remained the "gold standard" surgical treatment in patients with operable breast cancer. The systematic efforts to reduce the extend of this surgery in axillary region emerged at the turn of the 21 st century, as the results of NSAB B-32 study had been gradually applied into praxis (e.g. Harlow and Krag, 2001). This study compared mortality and morbidity of two cohorts of women with breast cancer: one cohort underwent only sentinel lymph node biopsy before treatment, while in the second one the biopsy was coupled with axillary lymph node dissection without the presence of nodal metastases. The initial argument of pathologists was that axillary lymph node dissection is the method of choice in cancer staging, however the results of this study started to gain ground in the medical community for an alternative concept of sentinel lymph node evaluation in breast cancer management (Harlow and Krag, 2001). Progressively more available and more broadly applied screening strategies finally revealed, that in about $75 \%$ of patients with histopathologicaly confirmed positive axillary sentinel lymph node, this is the only lymph node containing metastatic cancer cells. A more 
410-416

recent ACOSOG Z-0011 (American College of Surgeons Oncology Group Z-0011 Trial) study, which evaluated 64883 cases of breast cancer patients between 2005 and 2010 came to the conclusion that in case of one or two positive sentinel lymph nodes, it is not necessary to perform the complete axillary lymph node dissection. This conclusion was founded on the survival analysis, which revealed that the difference in five-year disease-free survival between two groups of patients with positive sentinel lymph node, who either underwent or skipped axillary lymph node dissection, was only about $1 \%$ (Ainsworth et al, 2013).

\section{The history of sentinel node examination}

On the grounds of the aforementioned, it can be said that sentinel lymph node biopsy is highly advantageous and relatively new approach in the management of malignant tumors, even though the first knowledge regarding its clinical application dates back to last decades of the 20th century. For the sake of complexity of this historical account, we present also a brief history of the sentinel lymph node discovery.

Rudolf Virchow (1821-1902), a famous German physician, who significantly contributed to the current status of histopathology as respected and important scientific discipline, was among the pioneers, who pointed out to the importance of lymph nodes as "defensive barriers" (Bekker and Meijer, 2008). In his honor, an eponym "Virchow's node" is used for a left supraclavicular lymph node, located behind the sternal end of the corresponding clavicle, whose enlargement signifies a possible lymphatic metastatic dissemination of cancer originating in organs of the gastrointestinal tract, e.g. stomach or colon cancer (Ohchi et al, 2014). The Virchow's theory can also partially explain, why the aforementioned Halstedt's en bloc lymph node resection was brought to the foreground in the following years.

The term sentinel lymph node is attributed to A. E. Gould and his co-workers, who authored a paper "Observations on a "sentinel node" in cancer of the parotid" published in the journal Cancer in 1960. This concept of sentinel lymph node originated in their earlier observations from 1951 (Gould et al, 1960). During a surgery of parotid gland cancer (total parotidectomy), the authors noticed a normally looking lymph node at the confluence of vena facialis anterior et posterior. However, the subsequent histopathological evaluation of the lymph node revealed the presence of metastatic cancer cells. This discovery motivated Gould to implement the approach of perioperative evaluation of the lymph node biopsy, and in the case negative result, consequent adjustment of the surgical strategy, meaning that the surgery could be carried out in a much more conservative manner. During the following years, sentinel lymph node in penis cancer was also identified. Ramond M. Cabañas in 1977 used his lymphographic studies, which helped him to identify a direct lymphatic connection between penis and lymph nodes associated with the vena epigastrica superficialis (Cabanas, 1977).

In 1970, Kett and co-authors decided to map the mammary lymphatic drainage using the injection of dye. They described the lymphatic flow into an isolated lymph node, known today as
Sorgius node, and subsequent drainage into multiple lymphatic vessels and nodes located around vena axillaris (Kett et al, 1970). Sorgius node belongs to the group of nodi lymphatici axillares pectorales, located in close vicinity to the mammary gland, adjacent to the deep surface of the $m$. pectoralis major. Sorgius node is the largest of the group, found near the third digitation (muscular slip) of the $m$. serratus anterior. The metastases from the carcinoma located in the upper outer quadrant are likely to reach this lymph node first. Using mammary lymphoscintigraphy, Christensen et al. (1980) described regional lymph nodes this tributary region drains to.

\section{The methods of sentinel node bioptic sample evaluation}

After a sentinel lymph node is successfully identified, next essential step is the harvesting of the lymph node and examination of the obtained bioptic sample. The perioperative modality of the excision and subsequent processing depends on the chosen approach of the sample evaluation. Currently, sentinel lymph node biopsy is standard and firmly established pathological diagnostic tool for invasive breast cancer staging in patients with $\mathrm{cN} 0$ clinical stage of the axilla. There is a variety of methods used by pathologists from common histopathological examination, through serial sectioning, to immunohistochemistry, and even methods of molecular biology, e.g. polymerase chain reaction. The usage of multitude of different techniques is a reasonable strategy, as common morphological evaluation is insufficient in some cases of lymphatic spread of the cancer cells, so it can be considered a preventive measure, which ensures that no metastatic process will be left undetected (Karampelias et al, 2019, Zahoor et al, 2017).

Modern histopathological diagnostic approaches revealed that in as many as $1 / 3$ of all cases with pN0 (i.e. without metastases) result of the common histopathological examination, metastatic cancer cells were actually present in the lymph nodes (Chagpar, 2010). In respect of these findings, The American Joint Committee on Cancer put together a classification of lymph node metastases, distinguishing three main groups (Edge et al, 2009):

- isolated cancer cells, no cell cluster is larger than $0.2 \mathrm{~mm}, \mathrm{pN} 0$ (i+),

- micrometastases with overall size of 0.2-2 mm, pN1mi,

- macrometastases with overall size of $2 \mathrm{~mm}$ and more.

The real significance of these minor nodal changes (micrometastases or isolated tumor cells) is still a subject of discussion (Dutta et al, 2019). A Dutch retrospective MIRROR trial focused on the survival rate of patients in complete remission with diagnosed pN0, in comparison to those patients with detected minor nodal changes. The results showed that the presence of such changes has a negative impact on the survival rate (de Boer, 2009), on the other hand, two large trials ACOSOG Z0010 a NSABP-32 didn't confirm any statistically significant negative impact of immunohistochemically proved occult cancer infiltration of the lymph nodes on the survival rate (Zahoor et al, 2017).

Abovementioned bioptic approaches can be classified from the perspective of the time management of the surgery into two categories. The first category encompasses the classic histopathology, 
i.e. postoperative evaluation of formalin-fixed paraffin-embedded tissue blocks. With respect to accuracy, this approach is considered optimal, although the very nature of its methodological steps makes it unavoidable for a patient to undergo second surgery. This can be bypassed by perioperative evaluation of frozen sections, which is much quicker, though this technique has a higher demand for technical and personal resources, and the rapidness also results in inferior quality of the final tissue specimen image (Castellano et al, 2012). This lower morphological quality of the slide prepared according to the principles of frozen section procedure rises the risk of false negativity in case of subtle metastases, which represent inconspicuous changes that can easily go unnoticed if the microscopic image resolution is not high enough. Especially cautious a diagnostician needs to be when examining a frozen section-produced slide of potential delicate metastases of lobular carcinoma, which is typical by infiltrative growth and indistinctive cytological characteristics (Layfield et al, 2011).

Formalin-fixed paraffin-embedded sections are also advantageous because they are easy-to-use for immunohistochemical analysis of selected markers/antigens. This applies not only for the sentinel lymph node and cancer cells detection, but also for the examination of the cancer tissue itself. This is particularly important in those tumors, which have variable biological potential, e.g. ductal carcinoma in situ with or without micrometastases. In these cases, Wan et al. (2018) recommend to employ a combination of antibodies against estrogen receptor $\alpha$, progesterone receptor, human epidermal growth factor receptor 2 (HER-2), and marker of cellular proliferation Ki-67. The cited authors also found out that ducal carcinoma in situ with microinvasion is a more aggressive subtype, whose cells are strongly positive for HER-2, while at the same time only weakly positive for estrogen receptor $\alpha$ and progesterone receptor. Moreover, Di Cesare et al. (2017) concluded that patients with HER-2 positive ductal carcinoma observed during the course of 8 years were more likely to experience episodes of cancer recurrence. This completes the panoptic view, which underlines that modern histopathological examination using the method of immunohistochemistry has still its righteous place in the diagnostic process of breast cancer, even in the times of brisk development of molecular biology.

A modern approach is a technique known as One-Step Nucleic Acid Amplification (OSNA). This technique of molecular biology enables a rapid perioperative assessment of axillary sentinel lymph node status. It is based on the quantification of mRNA copies of cytokeratin 19 (Brambilla et al, 2015, Shiino et al, 2019, Shimazu et al, 2019).

\section{Current knowledge about the significance of sentinel node positivity / negativity}

One of the most important questions, when considering the optimal strategy for breast cancer surgery is whether the complete axillary lymph node dissection is necessary in case of positive sentinel lymph node. The question was outlined in Z0011 randomized trial by American College of Surgeons Oncology Group (Giuliano et al, 2010). The methodology of this trial employed two cohorts - one comprised 446 patients, who underwent only sentinel lymph node biopsy, while the second cohort of 445 patients also underwent subsequent complete axillary lymph node dissection. The average number of excised lymph nodes was two vs. seventeen lymph nodes in the first and second cohort, respectively. After a 6-year follow-up, the authors concluded that the differences between the two cohorts with regard to local or regional recurrence of the disease was statistically insignificant. The summary of the results indicated that despite a potential risk of metastasis occurrence in axillary lymph nodes, sentinel lymph node biopsy (i.e. conservation of the other axillary lymph nodes) alone was sufficient and could be considered as adequate therapy in selected category of patients with diagnosed early-stage breast cancer undergoing adjuvant systemic therapy (Giuliano et al, 2010). Next year, the team of cited authors confirmed this preliminary result by concluding that sentinel lymph node biopsy in comparison to complete axillary lymph node dissection didn't decrease patients' survival rate (Giuliano et al, 2011). These studies, along with plenty of others, significantly altered the insight of medical professionals into this issue, bringing in the principal take-home-message that in carefully selected indications, axillary lymph nodes can be preserved. Similar conclusion were also made in newer papers, e.g. by Caudle et al. (2012). Last year, a 10-year follow-up IBCS 23-10 trial was published, which monitored patients with breast carcinoma at the size of $5 \mathrm{~cm}$ or smaller, and with micrometastases in the sentinel lymph nodes (smaller than 2 $\mathrm{cm}$ ). The trial concluded that complete axillary lymph node dissection was not necessary in this group of patients (Galimberti et al, 2018).

Current surgical management of early-stage breast cancer can be summed up, according to the recommendations by Guliano et al (2017), as follows: In patients with T1 or T2 primary invasive breast cancer $(<5 \mathrm{~cm})$, with clinically negative axillary lymphadenopathy, even in the presence of one or two sentinel lymph nodes positive for metastases, it is not necessary to perform complete axillary lymph node dissection, considering that 10 -year survival rate is almost the same as if the complete dissection was performed. These are the results of follow-up ACOSOG Z0011 trial, already cited in the beginning of this section.

All these results can be meta-analyzed as follows: in cases of pT1-2, N0, M0, clinically and preoperatively diagnosed micrometastases in sentinel lymph nodes at the size of $0.2-2 \mathrm{~mm}$, or even with macrometastases in at most two sentinel lymph nodes, complete axillary lymph node dissection is not indicated. The surgery in the axilla is sequenced in a specific manner: to begin with, the first sentinel lymph node is excised and histopathologicaly examined. If it's negative, complete axillary lymph node dissection is omitted. In case of positivity, the second node is subsequently extirpated. If it's negative, the surgery is over. If the diagnosis is positive, the third sentinel lymph node is further evaluated. Also, if the third sentinel lymph node is negative, the surgery can be concluded, however in case of positivity, there is also an option to finish the surgery and thus preserve the rest of the nodes, but exclusively in case of adjuvant therapy and radiotherapy of the axilla and the whole breast. 
$410-416$

\section{Concluding remarks}

Breast cancer treatment can be considered one of the most progressive therapeutic approaches in the medical field of oncology. Thanks to the advancements of genetics and molecular biology, the treatment has become more causal as well as more available (Kim et al, 2019). The implementation of novel diagnostic methods has manifested in the decrease of morbidity and mortality of this type of cancer, even though the incidence has risen over the past few years. This review paper discusses the historical background of the concept of sentinel lymph node and also focuses on biopsy modalities and clinical significance of the positivity of sentinel lymph node(s) relevant for the anatomical location of given primary breast cancer tissue. It stems from the dynamics of the metastatic process of this invasive neoplasm, which spreads via the lymphatic route - sentinel lymph node is the first way point of metastatic cells, before they reach other lymph nodes, and eventually distant locations of rest of the body.

Sentinel lymph node biopsy has significantly altered the strategy of surgical treatment of some solid tumors, and at the same time, provided a stimulus for reconsideration of the outlook of the management of many other oncological diseases. Sentinel lymph node biopsy is now established as a standard procedure in the management of malignant melanoma (Prieto, 2017), including some mucosal melanomas (anal, genital), but also other skin tumors (particularly Merkel cell carcinoma), breast cancer, and tumors of penis and vulva. Less common, but nevertheless successful, the biopsy is also in colorectal carcinoma, cervical cancer, endometrial cancer, as well as carcinomas of the head, neck and thyroid gland (Fait, 2014, Jimenez-Heffernan et al, 2015).

The metastatic affection of axillary lymph node is today considered as an important prognostic factor, particularly in the initial stages of the breast cancer. Sentinel lymph node microstaging focused on the presence of occult metastases, has become a trend thanks to the increased availability of more detailed and refined histopathological and immunocytochemical methods. Although the sentinel lymph node biopsy definitely upgraded the breast cancer staging in patients with early diagnosis, the actual prognostic significance of micro- or even nanometastases is the subject of discussion. Modern oncological centers are thus engaged in resolving the issue whether metastases other than "classic" macrometastases also influence long-term survival of patients. Some studies have already shown that those patients with diagnosed isolated cancer cells and micrometastases, who had not received systemic adjuvant therapy, had much worse prognosis and survival rate. Other studies confirmed that sentinel lymph node micrometastases definitely require an additional therapy in effort to lower the risk of cancer relapse (Chvalný et al, 2010).

The deciding prognostic factor of breast cancer patient's survival is not exclusively dependent on the biological dignity and size of the tumor, axillary staging is also a variable that has to be taken into account. Sentinel lymph node biopsy is the method of choice in early-stage breast cancer. The conclusions of recent years' original papers as well as reviews have clearly accentuated the rationale for above described current modern approach to surgical treatment of breast cancer, and also have unambiguously declared that complete axillary lymph node dissection in early-stage breast cancer with limited sentinel lymph node micrometastases, did not rise patient's survival, but caused a lot of "collateral damage" in the form of serious side effects, often leading to chronic morbidity, which worsens a patient's quality of life despite the success of primary cancer treatment (Mytnik et al, 2011).

\section{References}

1. Ainsworth RK, Kollias J, Le Blanc A, De Silva P. The clinical impact of the American College of Surgeons Oncology Group Z-0011 trial - results from the Breast Surg ANZ National Breast Cancer Audit. Breast 2013; 22 (5): 733-735.

2. Bekker J, Meijer S. The historical perspective of the sentinel lymph node concept. Ned Tijdschr Geneeskd 2008; 152 (1): 38-45.

3. Bolster MJ, Bult P, Schapers RF, Meijer JW, Strobbe LJ, van Berlo CL, Klinkenbijl JH, Peer PG, Wobbes T, Tjan-Heijnen VC. Differences in sentinel lymph node pathology protocols lead to differences in surgical strategy in breast cancer patients. Ann Surg Oncol 2006; 13 (11): 1466-1473.

4. Brambilla T, Fiamengo, B, Tinterri, C, Testori, A, Grassi, MM, Sciarra A, Abbate T, Gatzemeier W, Roncalli M, Di Tommaso L. One-Step Nucleic Acid Amplification in Breast Cancer Sentinel Lymph Node: A Single Institutional Experience and a Short Review. Front Med (Laussane) 2015; $2: 37$.

5. Cabañas RM. An approach for the treatment of penile carcinoma. Cancer 1977; 39: 456-466.

6. Cabanas RM. Anatomy and biopsy of sentinel lymph nodes. Urol Clin North Am 1992; 19 (2): 267-276.

7. Castellano I, Macrì L, Deambrogio C, Balmativola D, Bussone R, Ala A, Coluccia C, Sapino A. Reliability of whole sentinel lymph node analysis by one-step nucleic acid amplification for intraoperative diagnosis of breast cancer metastases. Ann Surg 2012; 255 (2): 334-342.

8. Caudle AS, Hunt KK, Tucker SL, Hoffman K, Gainer SM, Lucci A, Kuerer HM, Meric-Bernstam F, Shah R, Babiera GV, Sahin AA, Mittendorf EA. American College of Surgeons Oncology Group (ACOSOG) Z0011: impact on surgeon practice patterns. Ann Surg Oncol 2012; 19 (10): 3144-3151.

9. Chagpar AB. Clinical significance of minimal sentinel node involvement and management options. Surg Oncol Clin N Am 2010; 19 (3): 493-505.

10. Choi HJ, Kim I, Alsharif E, Park S, Kim JM, Ryu JM, Nam SJ, Kim SW, Yu J, Lee SK, Lee JE. Use of Sentinel Lymph Node Biopsy after Neoadjuvant Chemotherapy in Patients with Axillary Node-Positive Breast Cancer in Diagnosis. J Breast Cancer 2018; 21 (4): 433-441.

11. Christensen B, Blichert-Toft M, Siemssen OJ, Nielsen SL. Reliability of axillary lymph node scintiphotography in suspected carcinoma of the breast. Br J Surg 1980; 67: 667-668.

12. Chvalný P, Straka V, Donát R, Malina J, Dyttert D, Sabol M, Duchaj B, Veselá J, Lehotská V, Rauová K, Galbavý Š, Macák D, Ďurčány V, Bíró C. Význam biopsie sentinelovej uzliny pri včasnom karcinóme prsníka. Rozhl Chir 2010; 89 (7): 395-401.

13. Darani HY, Yousefi M. Parasites and cancers: parasite antigens as possible targets for cancer immunotherapy. Future Oncol 2012; 8 (12): 1529-1535. 
14. de Boer M, van Deurzen CH, van Dijck JA, Borm GF, van Diest PJ, Adang EM,Nortier JW, Rutgers EJ, Seynaeve C, MenkePluymers MB, Bult P, Tjan-Heijnen VC. Micrometastases or isolated tumor cells and the outcome of breast cancer. N Engl J Med 2009; 361 (7): 653-663.

15. Di Cesare P, Pavesi L, Villani L, Battaglia A, Da Prada GA, Riccardi A, Frascaroli M. The Relationships between HER2 Overexpression and DCIS Characteristics. Breast J 2017; 23 (3): 307-314.

16. Dumitru D, Khan A, Catanuto G, Rocco N, Nava MB, Benson JR. Axillary surgery in breast cancer: the beginning of the end. Minerva Chir 2018; 73 (3): 314-321.

17. Dutta SW, Volaric A, Morgan JT, Chinn Z, Atkins KA, Janowski EM. Pathologic Evaluation and Prognostic Implications of Nodal Micrometastases in Breast Cancer. Semin Radiat Oncol 2019; 29 (2): 102-110.

18. Ebner F, Wöckel A, Janni W, Kreienberg R, Schwentner L, Wischnewsky M. Personalized axillary dissection: the number of excised lymph nodes of nodal-positive breast cancer patients has no significant impact on relapse-free and overall survival. J Cancer Res Clin Oncol 2017; 143 (9): 1823-1831.

19. Edge S, Byrd D, Compton C, Fritz AG, Greene F, Trotti A. AJCC Cancer Staging Manual. New York: Springer, 2009.

20. Fait V. Sentinelová biopsie, stručný nástin problematiky. Vnitř Lék 2014; 60 (5-6): 415-416.

21. Fisher B, Montague E, Redmond C, Deutsch M, Brown GR, Zauber A, Hanson WF, Wong A. Findings from NSABP Protocol No. B04-comparison of radical mastectomy with alternative treatments for primary breast cancer. I. Radiation compliance and its relation to treatment outcome. Cancer 1980; 46 (1): 1-13.

22. Galimberti V, Cole BF, Viale G, Veronesi P, Vicini E, Intra M, Mazzarol G, Massarut S, Zgajnar J, Taffurelli M, Littlejohn D, Knauer M, Tondini C, Di Leo A, Colleoni M, Regan MM, Coates AS, Gelber RD, Goldhirsch A, International Breast Cancer Study Group Trial 23-01. Axillary dissection versus no axillary dissection in patients with breast cancer and sentinel-node micrometastases (IBCSG 23-01): 10-year follow-up of a randomised, controlled phase 3 trial. Lancet Oncol 2018; 19 (10): 1385-1393.

23. Gillespie TC, Sayegh HE, Brunelle CL, Daniell KM, Taghian AG. Breast cancer-related lymphedema: risk factors, precautionary measures, and treatments. Gland Surg 2018; 7 (4): 379-403.

24. Giuliano AE, Ballman KV, McCall L, Beitsch PD, Brennan MB, Kelemen PR, Ollila DW, Hansen NM, Whitworth PW, Blumencranz PW, Leitch AM, Saha S, Hunt KK, Morrow M. Effect of Axillary Dissection vs No Axillary Dissection on 10-year Overall Survival Among Women With Invasive Breast Cancer and Sentinel Node Metastasis: The ACOSOG Z0011 (Alliance) Randomized Clinical Trial. JAMA 2017; 318 (10): 918-926.

25. Giuliano AE, Hunt KK, Ballman KV, Beitsch PD, Whitworth PW, Blumencranz PW, Leitch AM, Saha S, McCall LM, Morrow M. Axillary dissection vs no axillary dissection in women with invasive breast cancer and sentinel node metastasis: a randomized clinical trial. JAMA 2011; 305 (6): 569-575.

26. Giuliano AE, McCall L, Beitsch P, Whitworth PW, Blumencranz P, Leitch AM, Saha S, Hunt KK, Morrow M, Ballman K. Locoregional recurrence after sentinel lymph node dissection with or without axillary dissection in patients with sentinel lymph node metastases: the American College of Surgeons Oncology Group Z0011 randomized trial. Ann Surg 2010; 252 (3): 426-432.
27. Gould EA, Winship T, Philbin PH, Kerr HH. Observations on a "sentinel node" in cancer of the parotid. Cancer 1960; 13: 77-78.

28. Halsted CP, Benson JR, Jatoi I. A historical account of breast cancer surgery: beware of local recurrence but be not radical. Future Oncol 2014; 10 (9): 1649-1657.

29. Harlow SP, Krag DN. Sentinel lymph node - why study it: implications of the B-32 study. Semin Surg Oncol 2001; 20 (1): 224-229.

30. Huang NS, Liu MY, Chen JJ, Yang BL, Xue JY, Quan CL, Mo M, Liu GY, Shen ZZ, Shao ZM, Wu J. Surgical management of breast cancer in China: A 15-year single-center retrospective study of 18,502 patients. Medicine (Baltimore) 2016; 95 (45): e4201.

31. Jimenez-Heffernan A, Ellmann A, Sado H, Huić D, Bal C, Parameswaran R, Giammarile F, Pruzzo R, Kostadinova I, Vorster M, Almeida P, Santiago J, Gambhir S, Sergieva S, Calderon A, Young GO, Valdes-Olmos R, Zaknun J, Magboo VP, Pascual TN. Results of a Prospective Multicenter International Atomic Energy Agency Sentinel Node Trial on the Value of SPECT/CT Over Planar Imaging in Various Malignancies. J Nucl Med 2015; 56 (9): 1338-1344.

32. Joseph FJ, van Oepen A, Friebe M. Breast sentinel lymph node biopsy with imaging towards minimally invasive surgery. Biomed Tech (Berl) 2017; 62 (6): 547-555.

33. Karampelias V, Koukouras D, Tzorakoeleftherakis E, MariolisSapsakos UB, Chrysikos D. Breast cancer section analysis correlates with sentinel lymph node biopsies: Precision and topographic anatomy. Breast Dis 2019. doi: 10.3233/BD-180355. (in press).

34. Kett K, Varga G, Lukács L. Direct lymphography of the breast. Lymphology 1970; 1: 3-12.

35. Kim M, Suh DH, Lee KH, Eom KY, Toftdahl NG, Mirza MR, Kim JW. Major clinical research advances in gynecologic cancer in 2018. J Gynecol Oncol 2019; 30 (2): e18.

36. Koehler LA, Hunter DW, Blaes AH, Haddad TC. Function, Shoulder Motion, Pain, and Lymphedema in Breast Cancer with and Without Axillary Web Syndrome: An 18-Month Follow-Up. Phys Ther 2018; 98 (6): 518-527.

37. Layfield DM, Agrawal A, Roche H, Cutress RI. Intraoperative assessment of sentinel lymph nodes in breast cancer. Br J Surg 2011; 98 (1): 4-17.

38. Lee JH, Ryu KW, Lee SE, Cho SJ, Lee JY, Kim CG, Choi IJ, Kook MC, Kim MJ, Park SR, Lee JS, Nam BH, Kim YW. Learning curve for identification of sentinel lymph node based on a cumulative sum analysis in gastric cancer. Dig Surg 2009; 26 (6): 465-470.

39. Mytnik M, Petrík J, Hanudel' J, Wereb M, Klc J, Straka L. Prínos vyšetrenia sentinelovej uzliny pri včasnom karcinóme prsníka. Rozhl Chir 2011; 90 (6): 343-347.

40. Niebling MG, Pleijhuis RG, Bastiaannet E, Brouwers AH, van Dam GM, Hoekstra HJ. A systematic review and meta-analyses of sentinel lymph node identification in breast cancer and melanoma, a plea for tracer mapping. Eur J Surg Oncol 2016; 42 (4): 466-473.

41. Ohchi T, Akagi Y, Kinugasa T, Ishibashi Y, Tanaka N, Fujino S, Kibe S, Yuge K, Sasatomi T, Mizobe T, Oka Y, Hong KD, Shirouzu K. Virchow lymph node metastatic recurrence of sigmoid colon cancer with severe lymph node metastases successfully treated using systemic chemotherapy combined with radiotherapy. Anticancer Res 2013; 33 (7): 2935-2940.

42. Osborne MP. William Stewart Halsted: his life and contributions to surgery. Lancet Oncol 2007; 8: 256-265. 
410-416

43. Prieto VG. Sentinel Lymph Nodes in Cutaneous Melanoma. Clin Lab Med 2017; 37 (3): 417-430.

44. Rozsívalová-Lenzová E. Václav Trnka z Křovic, Professor of the Trnava University (Article in Czech: Václav Trnka z Křovic, český profesor na trnavské universitě). Casopís lékařu českých 1950; 89 (19): 559-560.

45. Shiino S, Yoshida M, Jimbo K, Asaga S, Takayama S, Maeshima A, Tsuda H, Kinoshita T, Hiraoka N. Two rare cases of endosalpingiosis in the axillary sentinel lymph nodes: evaluation of immunohistochemical staining and one-step nucleic acid amplification (OSNA) assay in patients with breast cancer. Virchows Arch 2019 Feb 12. doi: 10.1007/s00428-01902521-z. (in press).

46. Shimazu K, Miyake T, Okuno J, Naoi Y, Tanei T, Shimoda M, Kagara N, Kim SJ, Noguchi S. One-step Nucleic Acid Amplification Can Identify Sentinel Node-negative Breast Cancer Patients With Excellent Prognosis. Anticancer Res 2019; 39 (3): 1447-1454.

47. Varga I, Repka M, Kachlík D, Székely A. Václav Trnka - the story of an almost forgotten Czech-Austria-Slovakia-Hungarian anatomist of the 18th century, a founder of modern anatomy education in Hungary. FASEB J 2018; 32 (1 Suppl): Ib515.
48. Wan ZB, Gao HY, Wei L, Zhang AQ, Zhang JY, Wang Y, Wang DD, Zhang Y. Expression of estrogen receptor, progesterone receptor, human epidermal growth factor receptor 2, and Ki-67 in ductal carcinoma in situ (DCIS) and DCIS with microinvasion. Medicine (Baltimore) 2018; 97 (44): e13055.

49. Whitman GJ, AlHalawani RH, Karbasian N, Krishnamurthy R. Sentinel Lymph Node Evaluation: What the Radiologist Needs to Know. Diagnostics (Basel) 2019; 9 (1). pii: E12.

50. Wright JR. The Radicalization of Breast Cancer Surgery: Joseph Colt Bloodgood's Role in William Stewart Halsted's Legacy. Bull Hist Med 2018; 92 (1): 141-171

51. Zahoor S, Haji A, Battoo A, Qurieshi M, Mir W, Shah M. Sentinel Lymph Node Biopsy in Breast Cancer: A Clinical Review and Update. J Breast Cancer 2017; 20 (3): 217-227.

52. Kachlik D, Varga I, Szekely AD. The legacy of Vaclav Trnka: modern medical education in Slovakia and Hungary in the eighteenth century. SurgRadiolAnat 2019. doi: 10.1007/s00276-019-02251-6.

Received February 28, 2019. Accepted April 9, 2019. 